Case Report

\title{
Primary Hyperparathyroidism and Hyperthyroidism in a Patient with Myotonic Dystrophy: A Case Report and Review of the Literature
}

\author{
Yosra Cherif, Baha Zantour, Wafa Alaya, Olfa Berriche, \\ Samia Younes, and Mohamed Habib Sfar \\ Department of Endocrinology and Internal Medicine, Tahar Sfar University Hospital of Mahdia, Hiboun District, 5100 Mahdia, Tunisia
}

Correspondence should be addressed to Yosra Cherif; cherifyousra2011@gmail.com

Received 11 April 2015; Accepted 19 May 2015

Academic Editor: Wayne V. Moore

Copyright (C) 2015 Yosra Cherif et al. This is an open access article distributed under the Creative Commons Attribution License, which permits unrestricted use, distribution, and reproduction in any medium, provided the original work is properly cited.

\begin{abstract}
Various endocrine manifestations are commonly described in myotonic dystrophy (MD), including primary hypogonadism, diabetes mellitus, and thyroid and parathyroid dysfunction. We describe a 46-year-old woman with a family history of MD with her son. She was diagnosed with cardiac arrhythmia and required the implantation of a pacemaker. She was noted to have a bilateral cataract. She complained of muscle weakness, diffuse myalgia, and palpitation. The electromyography (EMG) showed myotonic discharges. Laboratory tests showed high serum calcium $2.83 \mathrm{mmol} / \mathrm{L}$, serum phosphate $1.2 \mathrm{mmol} / \mathrm{L}$, parathormone $362.5 \mathrm{pg} / \mathrm{mL}$, thyroid stimulating hormone TSH $0.02 \mathrm{mIU} / \mathrm{L}$ (normal range: 0.34-5.6 mIU/L), FT4 $21.17 \mathrm{ng} / \mathrm{mL}$, and negative antithyroperoxidase antibodies. Cervical ultrasound revealed a multinodular goiter. The $99 \mathrm{mTc}-\mathrm{MIBI}$ scintigraphy localized a lower right parathyroid adenoma. The clinical data, the family history of MD, EMG data, and endocrine disturbances were strongly suggestive of MD associated with hyperthyroidism and primary hyperparathyroidism.
\end{abstract}

\section{Introduction}

Myotonic dystrophy (MD) is an autosomal dominant disorder that results from an expanded CTG repeat in a myotonic dystrophy protein kinase (DMPK) gene on chromosome 3 or 19. It is the most common muscular dystrophy in adults. The disease is characterized by muscle weakness, dystrophic changes in neuromuscular tissues, frontal baldness, cataracts, cardiac disorder, and mental impairment with the development of the disease process. Various endocrine manifestations are commonly described, including primary hypogonadism, diabetes mellitus, and thyroid and parathyroid dysfunction [1]. A few cases of hyperthyroidism or hypothyroidism associated with MD have been reported, but there are only 2 reports, to our knowledge, concerning $\mathrm{MD}$ associated with primary hyperparathyroidism (PHP) and hyperthyroidism $[2,3]$. Herein, we describe an association of PHP and hyperthyroidism in a patient with MD and we reviewed all cases reported in the literature.

\section{Case Report}

A 46-year-old woman was admitted in 2010 for investigation of hypercalcemia discovered during recurrent nephrolithiasis. Her family history was noteworthy with cardiac arrhythmia in two dead sisters and nephrolithiasis in another sister. Her son was diagnosed with MD at the age of 24 years. Five years ago, an arrhythmia was diagnosed and required the implantation of a pacemaker. She was noted to have a bilateral cataract. She complained of muscle weakness, diffuse myalgia, and palpitation. The weakness was gradually progressive in arms. Physical examination revealed percussion myotonia and the typical emaciated face of MD, hollow cheeks, drooping jaw, a peripheral neurogenic syndrome, and multinodular goiter. There was no exophthalmia. The electrocardiogram was normal. Hypercalcaemia was confirmed $2.83 \mathrm{mmol} / \mathrm{L}$. There were no symptoms directly attributable to hypercalcemia. Other laboratory tests showed serum phosphate $1.2 \mathrm{mmol} / \mathrm{L}$, urinary calcium $0.153 \mathrm{mmol} / \mathrm{kg} /$ day, creatinine 


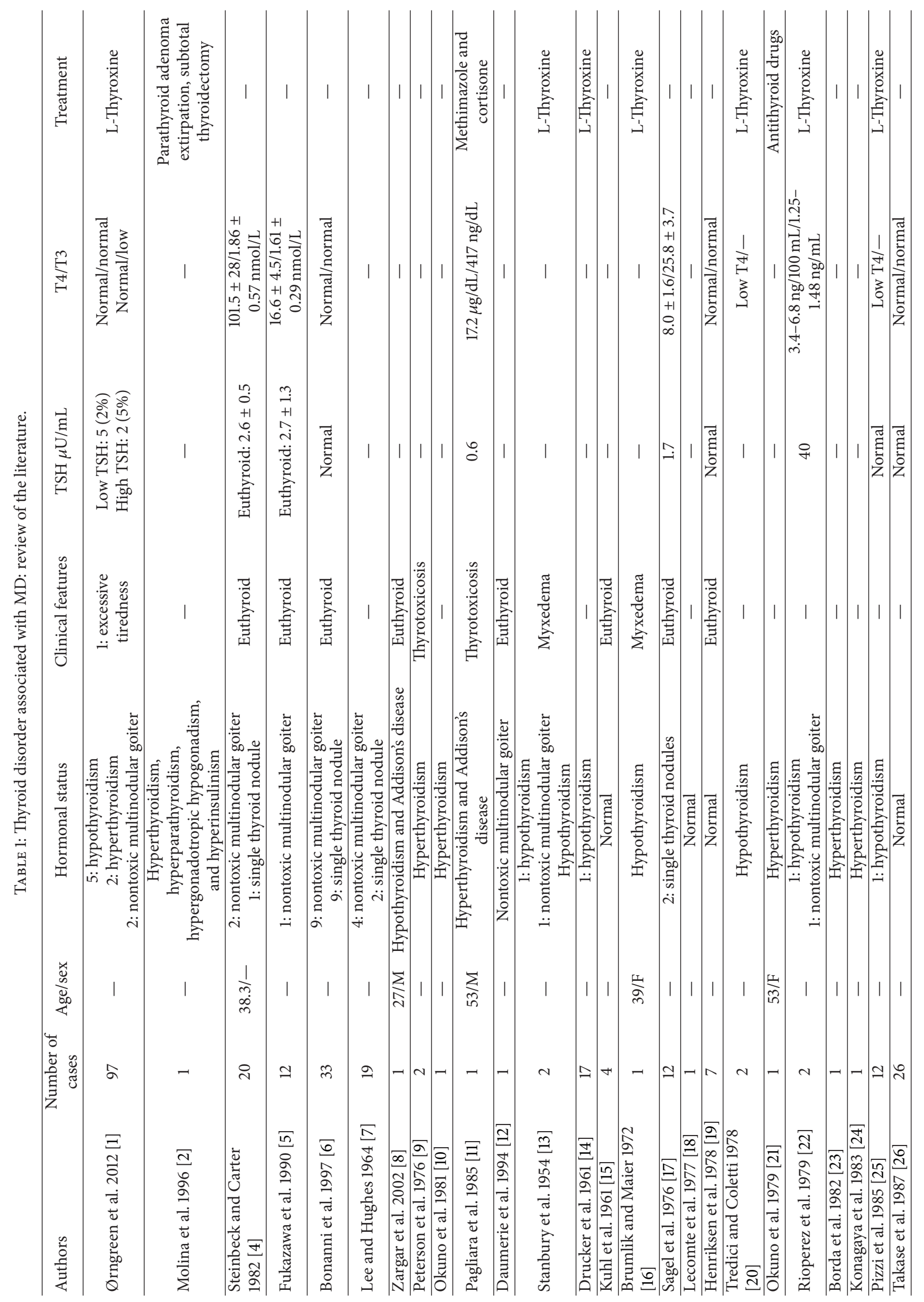




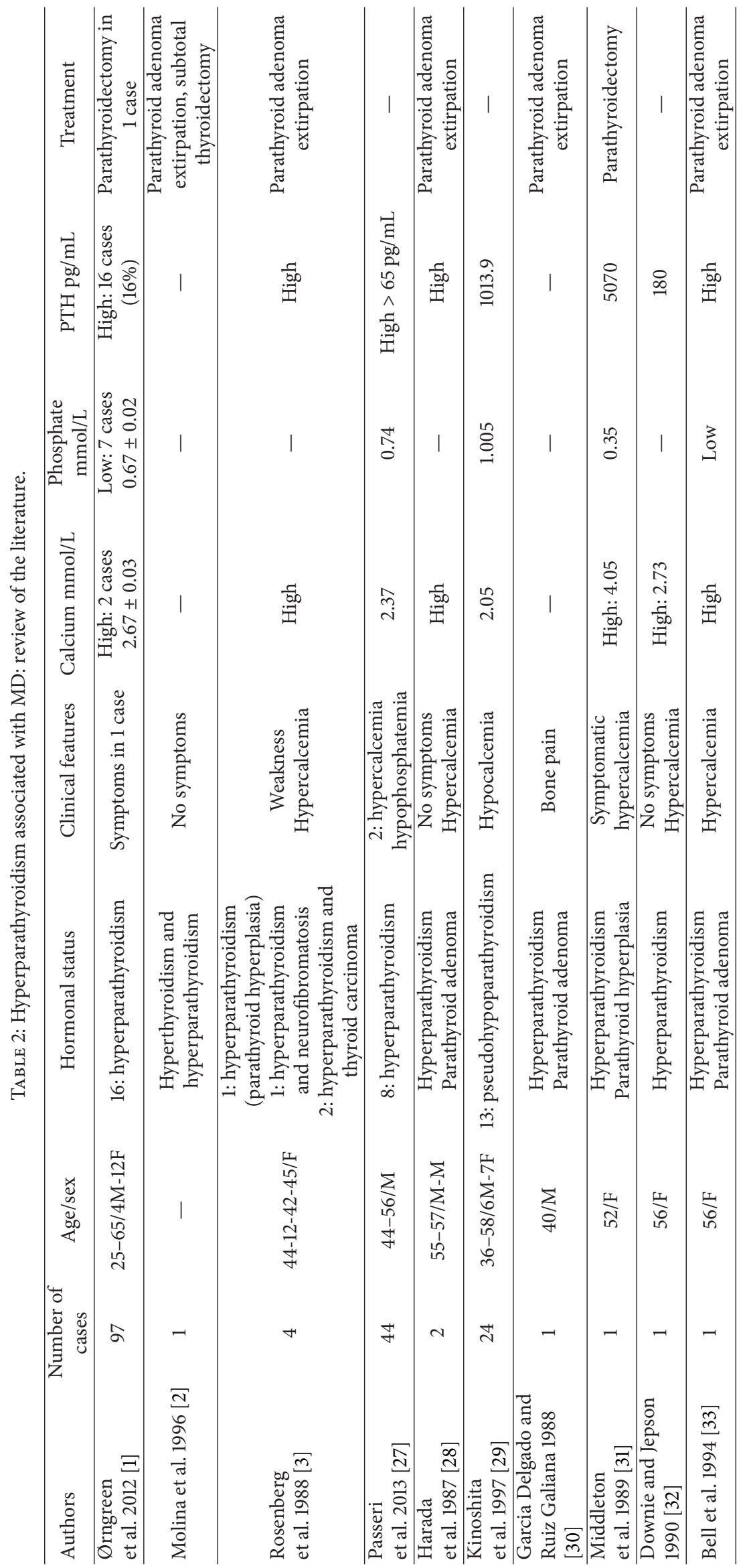


level $52 \mu \mathrm{mol} / \mathrm{L}$, alkaline phosphatase $97 \mathrm{IU} / \mathrm{L}$ (normal range: 45-245 IU/L), parathormone $362.5 \mathrm{pg} / \mathrm{mL}$ (normal range: $15-$ $65 \mathrm{pg} / \mathrm{mL}$ ), thyroid stimulating hormone TSH $0.02 \mathrm{mIU} / \mathrm{L}$ (normal range: $0.34-5.6 \mathrm{mIU} / \mathrm{L}$ ), FT4 $21.17 \mathrm{ng} / \mathrm{mL}$ (normal range: $6.09-12.2 \mathrm{ng} / \mathrm{mL}$ ), and negative anti-thyroperoxidase antibodies. Cervical ultrasound revealed a multinodular goiter with isoechogenic homogenic nodules with clear border and cystic cavities $(8 * 6 \mathrm{~mm})$. The $99 \mathrm{mTc}$-MIBI scintigraphy localized a lower right parathyroid adenoma. The electromyography (EMG) showed myotonic discharges. The bone mineral density (BMD) was normal. The clinical data, the family history of MD and arrhythmia in 2 sisters, EMG data, and endocrine disturbances were strongly suggestive of MD associated with hyperthyroidism and primary hyperparathyroidism (PHP). The patient was treated with benzylthiouracil, propranolol, and vitamin E. Euthyroidism was obtained after 2 years and the antithyroid drug was stopped. Four years later, MD is still in remission, and the alkaline phosphatase levels, serum creatinine and calcium, urinary calcium, and BMD are normal during follow-up.

\section{Discussion}

Our patient showed history, clinical, neurological, and electromyographic evidence of MD. Screening for endocrine disorders revealed PHP and hyperthyroidism.

The association of $\mathrm{MD}$ and endocrine and metabolic disturbances has been described by many authors [1]. Disorders of glucose metabolism were common and dominated by carbohydrates intolerance with hyperinsulinemia [1]; type 2 diabetes was less common (3\%) [1]. Even so, thyroid dysfunction has been reported; we reviewed 56 cases (Table 1). Plasma FT4 was blunted in 12 patients with MD (Table 1). Isolated hyperthyroidism was reported in 7 cases and it was associated with Addison disease in 2 cases (Table 1). Ørngreen et al. studied the thyroid profile of 97 patients with $\mathrm{MD}$ and showed only 5 cases of hypothyroidism, 2 cases of hyperthyroidism, and 2 other cases of nontoxic multinodular goiter [1]. Single or multiple thyroid nodules with euthyroid status (33 patients) were found in several studies [4-7].

The parathyroid dysfunction is less common in patients with MD (Table 2). Cases of PHP have been reported in 16.5 and $18 \%$, mainly parathyroid adenomas [1, 27]. Other few cases were reported [2, 28]. We recorded 34 cases of isolated PHP and 13 of pseudohypothyroidism in the literature (Table 2). Most of those patients exhibit parathyroid adenoma, and only one patient had parathyroid hyperplasia (Table 2).

The coexisting of several endocrinopathies with MD is rare (Tables 1 and 2). Association of Addison's disease and PHP was reported in 2 cases [8] (Table 1). In a review of the literature, we found one case of MD associated with hyperthyroidism and hyperparathyroidism (Table 1 ) and 2 cases of MD associated with PHP and thyroid carcinoma (Table 2). The first case described a patient who also suffered from hypergonadotropic hypogonadism and hyperinsulinism [2]. At surgery, a parathyroid adenoma was extirpated, and a subtotal thyroidectomy was performed [2]. Rosenberg et al. reported 2 cases of MD associated with parathyroid adenoma and thyroid carcinoma treated with parathyroidectomy and thyroidectomy [3]. To our knowledge, this publication is the third case report of MD associated with simultaneous hyperthyroidism and hyperparathyroidism.

Muscular disorders are often frequent in patients with thyrotoxicosis [34]. It can manifest as myotonic features [9, 34]. Several authors reported yet that the treatment of patients with hyperthyroidism improved myotonic symptoms [2, 911, 34]. Then, it may be hard to distinguish them from myotonia related to MD in the absence of electromyographic study. These myotonic discharges are nonspecific and can be experienced in other various diseases such as Duchenne muscular dystrophy, hypokalemic periodic paralysis, drug induced myotonia, and thyrotoxicosis [34-36]. Our patient had a family history of MD, cataracts, and cardiac disorders and she continued to show clinical evidence of myotonia 2 years after successful medical treatment with benzylthiouracil.

Steinbeck and Fukazawa suggested that MD may result from a defect in cellular membrane function $[4,5]$. It is possible that the response to activation of $\mathrm{TRH}$ receptors on cell membrane is abnormal, which might explain the reduced TSH response to TRH and the increased incidence of goiter in even euthyroid patients with $\mathrm{MD}[4,5]$. Only one case report showed a larger amplification of CTG triplets in thyroid in a patient with MD and associated nodular goiter and suggests that repeated amplification of CTG triplet in thyroid tissue contributes to its dysfunction [12]. Ørngreen et al. showed a correlation between CTG expansion size with plasma PTH, phosphate, and serum calcium [1, 29]. Similar findings were described by Kinoshita et al. [37]. In addition, muscle weakness is a well-known complication of hyperparathyroidism. Passeri et al. showed a negative correlation between muscle strength in MD and PTH levels [27].

In conclusion, coexistence of hyperthyroidism and primary hyperparathyroidism may be more prevalent than what was previously recognized. Although further studies are needed to clarify the link between these two disorders and MD, the present case emphasizes the prominence of screening of parathyroid and thyroid function in patients with MD.

\section{Conflict of Interests}

The authors report no conflict of interests.

\section{References}

[1] M. C. Ørngreen, P. Arlien-Søborg, M. Duno, J. M. Hertz, and J. Vissing, "Endocrine function in 97 patients with myotonic dystrophy type 1," Journal of Neurology, vol. 259, no. 5, pp. 912920, 2012.

[2] M. J. Molina, J. I. Lara, P. Riobo et al., "Primary hyperthyroidism and associated hyperparathyroidism in a patient with myotonic dystrophy: steinert with hyperthyroidism and hyperparathyroidism," The American Journal of the Medical Sciences, vol. 311, no. 6, pp. 296-298, 1996. 
[3] N. L. Rosenberg, J. H. Diliberti, A. M. Andrews, and N. R. Buist, "Myotonic dystrophy and hyperparathyroidism: association with neurofibromatosis and multiple endocrine adenomatosis type 2A," Journal of Neurology, Neurosurgery \& Psychiatry, vol. 51, no. 12, pp. 1578-1580, 1988.

[4] K. S. Steinbeck and J. N. Carter, "Thyroid abnormalities in patients with myotonic dystrophy," Clinical Endocrinology, vol. 17, no. 5, pp. 449-456, 1982.

[5] H. Fukazawa, T. Sakurada, K. Yoshida et al., "Thyroid function in patients with myotonic dystrophy," Clinical Endocrinology, vol. 32, no. 4, pp. 485-490, 1990.

[6] G. Bonanni, S. Pennazzato, C. Santarossa et al., "Myotonic dystrophy: lack of correlation between CTG expansion and thyroid and carbohydrate status," Basic and Applied Myology, vol. 7, no. 5, pp. 345-349, 1997.

[7] F. I. Lee and D. T. D. Hughes, "Systemic effects in dystrophia myotonica," Brain, vol. 87, no. 3, pp. 521-536, 1964.

[8] A. H. Zargar, M. H. Bhat, M. A. Ganie et al., "Polyglandular endocrinopathy in myotonic dystrophy: letter to editor," $\mathrm{Neu}$ rology India, vol. 50, no. 1, pp. 105-106, 2002.

[9] D. M. Peterson, J. V. Bounds Jr., and W. E. Karnes, "Clinical observations on thyrotoxicosis coexisting with myotonic dystrophy," Mayo Clinic Proceedings, vol. 51, no. 3, pp. 176-179, 1976.

[10] T. Okuno, K. Mori, K. Furomi, T. Takeoka, and K. Kondo, "Myotonic dystrophy and hyperthyroidism," Neurology, vol. 31, no. 1, pp. 91-93, 1981.

[11] S. Pagliara, E. Spagnuolo, L. Ambrosone, A. Barbato, P. Tesauro, and M. Rambaldi, "Hyperthyroidism and Addison's disease in a patient with myotonic dystrophy," Archives of Internal Medicine, vol. 145, no. 5, pp. 919-920, 1985.

[12] C. Daumerie, N. Lannoy, J.-P. Squifflet, G. Verellen, and C. Verellen-Dumoulin, "High CTG repeat number in nodular thyroid tissue from a myotonic dystrophy patient," Journal of Medical Genetics, vol. 31, no. 11, pp. 891-892, 1994.

[13] J. B. Stanbury, R. R. Goldsmith, and M. Gillis, "Myotonic dystrophy associated with thyroid disease," The Journal of Clinical Endocrinology \& Metabolism, vol. 14, no. 11, pp. 14371443, 1954.

[14] W. D. Drucker, L. P. Rowland, K. Sterling, and N. P. Christy, "On the function of the endocrine glands in myotonic muscular dystrophy," The American Journal of Medicine, vol. 31, pp. 941950, 1961.

[15] W. J. Kuhl, I. S. Halper, and R. M. Dowben, "Thyroxine and triiodothyronine turnover studies in dystrophia myotonica," Journal of Clinical Endocrinology and Metabolism, vol. 21, pp. 1592-1595, 1961.

[16] J. Brumlik and R. J. Maier, "Myxedema and myotonic dystrophy," Archives of Internal Medicine, vol. 129, no. 1, pp. 120-122, 1972.

[17] J. Sagel, L. A. Distiller, J. E. Morley, and H. Isaacs, "Letter: normal thyrotropin-releasing hormone response in myotonia dystrophica," Archives of Neurology, vol. 33, no. 7, p. 520, 1976.

[18] P. Lecomte, F. Lamisse, J. H. Soutoul, and J. J. Morel, "Endocrine aspects of Steinert's disease," Semaine des Hopitaux, vol. 53, no. 4, pp. 227-233, 1977.

[19] O. A. Henriksen, J. A. Sundsfjord, and R. Nyberg Hansen, "Evaluation of the endocrine functions in dystrophia myotonica," Acta Neurologica Scandinavica, vol. 58, no. 3, pp. 178-189, 1978.

[20] G. Tredici and A. Coletti, "Dystrophia myotonica and hypothyroidism," Journal of Neurology, vol. 218, no. 3, pp. 215-218, 1978.
[21] T. Okuno, K. Mori, T. Aizawa, T. Takeoka, and K. Furumi, "A case of myotonic dystrophy associated with hyperthyroidism (author's transl)," Nihon Naika Gakkai Zasshi, vol. 68, no. 1, pp. 74-80, 1979.

[22] E. Rioperez, J. M. Botella, A. Palacio, I. Abaitua, J. L. Trueba, and J. R. Ricoy-Campo, "Myotonic dystrophy associated with thyroid disease," Journal of the Neurological Sciences, vol. 43, no. 3, pp. 357-366, 1979.

[23] I. A. Borda, J. R. Morales, V. G. Camargo, C. F. Miranda, and A. P. Pérez-Medel, "Hyperthyroidism and Steinert's disease. Presentation of a new case and review of the literature," Revista Clinica Espanola, vol. 164, no. 5, pp. 343-345, 1982.

[24] Y. Konagaya, H. Honda, M. Konagaya, S. Yanagimoto, T. Sakakibara, and T. Takayanagi, "Myotonic dystrophy associated with hyperthyroidism," Nihon Naika Gakkai Zasshi, vol. 72, no. 10, pp. 1391-1397, 1983.

[25] A. Pizzi, S. Fusi, G. Forti, and G. Marconi, "Study of endocrine function in myotonic dystrophy," The Italian Journal of Neurological Sciences, vol. 6, no. 4, pp. 457-467, 1985.

[26] S. Takase, N. Okita, H. Sakuma et al., "Endocrinological abnormalities in myotonic dystrophy: consecutive studies of eight tolerance tests in 26 patients," Tohoku Journal of Experimental Medicine, vol. 153, no. 4, pp. 355-374, 1987.

[27] E. Passeri, E. Bugiardini, V. A. Sansone et al., "Vitamin D, parathyroid hormone and muscle impairment in myotonic dystrophies," Journal of the Neurological Sciences, vol. 331, no. 1-2, pp. 132-135, 2013.

[28] S. Harada, T. Matsumoto, K. Ikeda, S. Fukumoto, Y. Ihara, and E. Ogata, "Association of primary hyperparathyroidism with myotonic dystrophy in two patients," Archives of Internal Medicine, vol. 147, 777, no. 4, p. 778, 1987.

[29] M. Kinoshita, T. Komori, T. Ohtake, R. Takahashi, R. Nagasawa, and K. Hirose, "Abnormal calcium metabolism in myotonic dystrophy as shown by the Ellsworth-Howard test and its relation to CTG triplet repeat length," Journal of Neurology, vol. 244, no. 10, pp. 613-622, 1997.

[30] E. Garcia Delgado and J. Ruiz Galiana, "Association of primary hyperparathyroidism with myotonic dystrophy in two patients," Archives of Internal Medicine, vol. 148, no. 1, pp. 237-241, 1988.

[31] P. G. Middleton, S. Posen, and G. Shannon, "Hyperparathyroidism in a patient with myotonic dystrophy," Journal of the Royal Society of Medicine, vol. 82, no. 4, article 227, 1989.

[32] A. Downie and E. M. Jepson, "Hyperparathyroidism in a patient with myotonic dystrophy," Journal of the Royal Society of Medicine, vol. 83, no. 1, p. 58, 1990.

[33] E. Bell, A. R. Lorimer, and J. Hinnie, "Association between myotonic dystrophy and primary hyperparathyroidism," Journal of International Medical Research, vol. 22, no. 5, pp. 296-298, 1994.

[34] A. W. Kung, "Neuromuscular complications of thyrotoxicosis," Clinical Endocrinology, vol. 67, no. 5, pp. 645-650, 2007.

[35] F. Hanisch, T. Kraya, M. Kornhuber, and S. Zierz, "Diagnostic impact of myotonic discharges in myofibrillar myopathies," Muscle \& Nerve, vol. 47, no. 6, pp. 845-848, 2013.

[36] D. F. de Almeida, T. V. Lissa, and A. C. Melo Jr., "Myotonic potentials in statin-induced rhabdomyolysis," Arquivos de Neuro-Psiquiatria, vol. 66, no. 4, pp. 891-893, 2008.

[37] M. Kinoshita, R. Takahashi, T. Hasegawa et al., "(CTG) ${ }_{n}$ expansions in various tissues from a myotonic dystrophy patient," Muscle and Nerve, vol. 19, no. 2, pp. 240-242, 1996. 


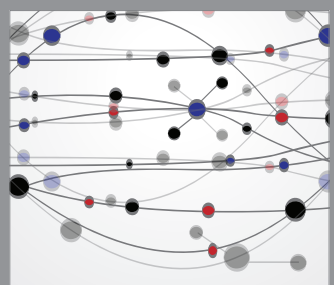

The Scientific World Journal
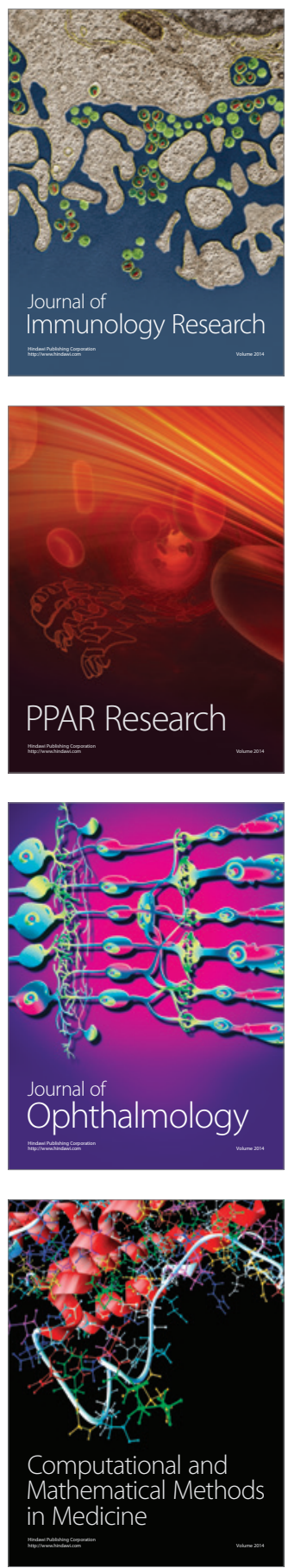

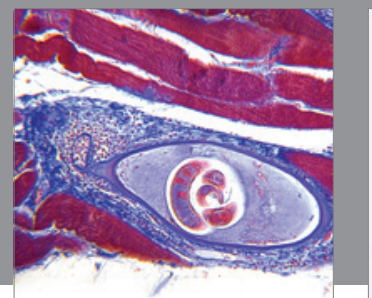

Gastroenterology

Research and Practice
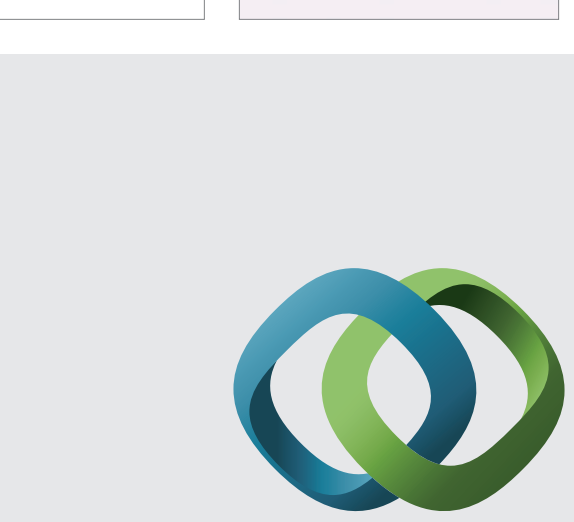

\section{Hindawi}

Submit your manuscripts at

http://www.hindawi.com
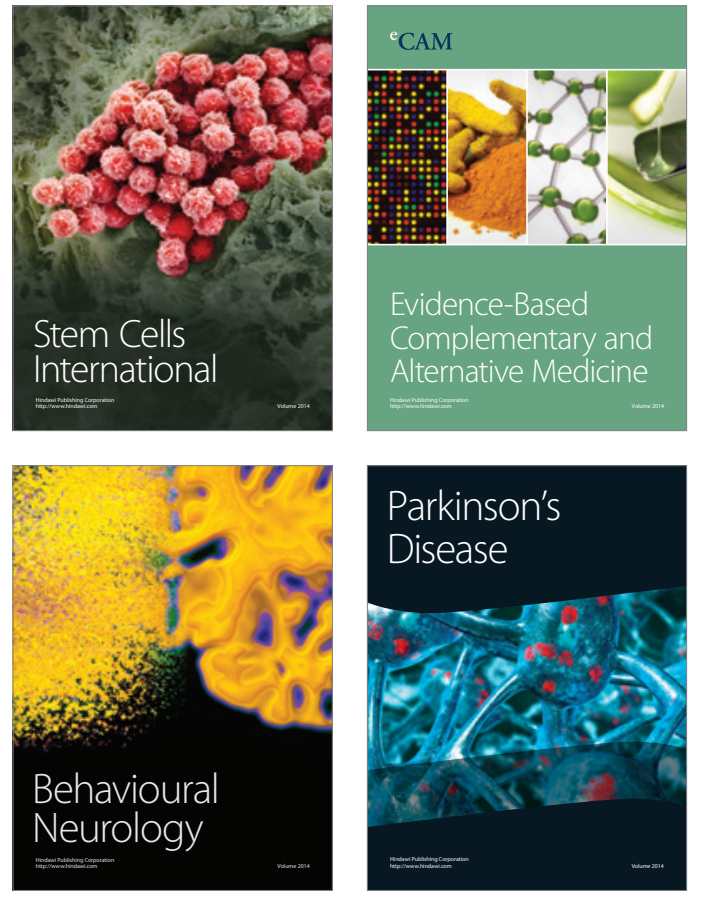
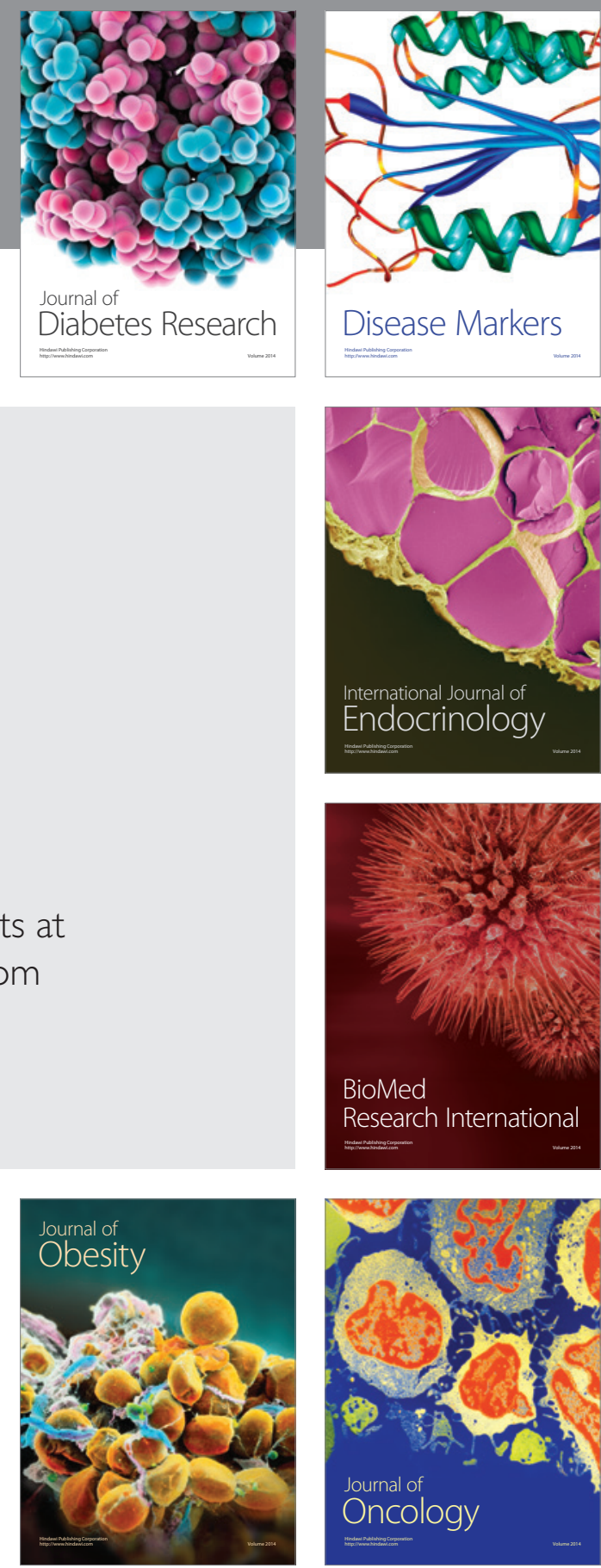

Disease Markers
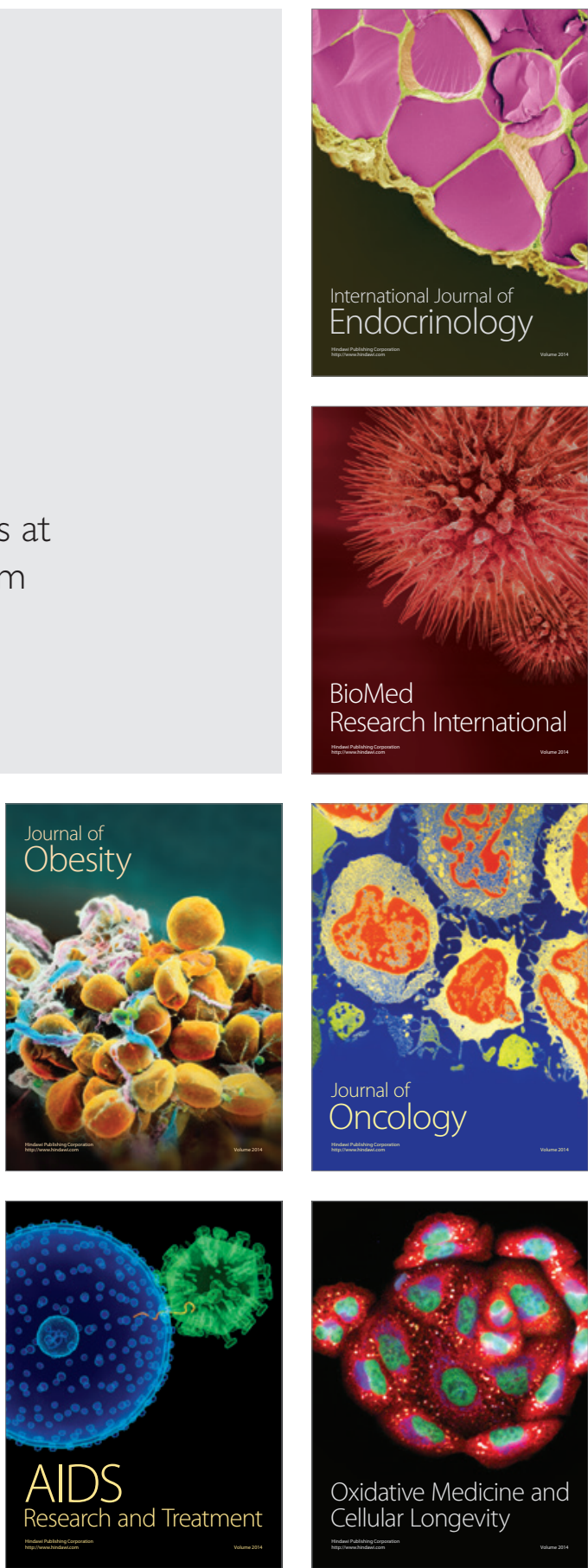